\title{
Avaliação da qualidade microbiológica do queijo-de-minas artesanal do Serro-MG
}

\author{
[Microbiological quality of artisanal minas cheese, manufactured in the region of Serro-MG] \\ L.M.F. Brant ${ }^{1}$, L.M. Fonseca ${ }^{1}$, M.C.C. Silva ${ }^{2}$ \\ ${ }^{1}$ Escola de Veterinária - UFMG \\ Caixa Postal 567 \\ 30123-970 - Belo Horizonte, MG \\ ${ }^{2}$ Fundação Ezequiel Dias - Belo Horizonte, MG
}

\begin{abstract}
RESUMO
Avaliaram-se a qualidade microbiológica do queijo-de-minas artesanal do Serro e a variação da microbiota do queijo recém-fabricado e no último dia de validade, após estocagem sob as condições recomendadas no rótulo. Foram analisadas 40 amostras de queijo, sendo 20 analisadas frescas, imediatamente após a coleta, e 20 no último dia de validade, após estocagem em câmara fria a $10^{\circ} \mathrm{C}$. As amostras foram analisadas para coliformes a $35^{\circ} \mathrm{C}$ e $45^{\circ} \mathrm{C}$, Staphylococcus coagulase positiva, Salmonella spp. e Listeria monocytogenes. Trinta e sete amostras (92,5\%) encontraram-se impróprias para o consumo humano, de acordo com os parâmetros estabelecidos pela resolução: RDC ANVISA n ${ }^{\circ} 12 / 01$, sendo a principal causa de condenação a contagem de Staphylococcus coagulase positiva. Nenhuma das amostras analisadas apresentou contaminação por Salmonella sp. ou Listeria monocytogenes. As contagens de Staphylococcus coagulase positiva dos queijos frescos foram mais altas $(\mathrm{P}<0,01)$ que as dos queijos analisados no último dia da validade.
\end{abstract}

Palavras-chave: queijo-de-minas artesanal, qualidade microbiológica

\begin{abstract}
The microbiological quality of artisanal minas cheese produced in the region of Serro-MG was evaluated. Cheeses were analyzed fresh and at the end of the shelf life, under specific storage conditions $\left(30\right.$ days, $\left.10^{\circ} \mathrm{C}\right)$. Forty samples of minas cheese were analyzed, twenty still fresh, and 20 after storage at $10^{\circ} \mathrm{C}$. The microbiological analyses were counts of fecal and total coliforms, and Staphylococcus coagulase positive; and search of Salmonella sp. and Listeria monocytogenes. Twenty-seven samples (92.5\%) were in disagreement with the Brazilian Standard, Resolution $n^{\circ} 12$ of January 12, 2001, from ANVISA (National Health Surveillance Agency), and Staphylococcus coagulase positive was the major contaminant. No sample was contaminated by Salmonella sp. or Listeria monocytogenes. During the storage, there was a decrease of countings in the population of Staphylococcus coagulase positive $(P<0.01)$.
\end{abstract}

Keywords: minas cheese, microbial quality

\section{INTRODUÇÃO}

A produção de queijo-de-minas artesanal a partir de leite cru é uma atividade tradicional em vários municípios de Minas Gerais. Essa atividade, além de ser a principal atividade geradora de renda dessas regiões, caracteriza a identidade sócio-cultural do estado (Furtado, 1980).

Segundo dados da EMATER, o queijo-de-minas artesanal é produzido por aproximadamente 27 mil pequenos e médios produtores em 519 dos

Recebido em 3 de julho de 2007

Aceito em 12 de novembro de 2007

Autor para correspondência (corresponding author)

E-mail: leorges@vet.ufmg.br 
823 municípios mineiros. A produção mensal gira em torno de 3.600 toneladas e movimenta cerca de 10 milhões de reais. Segundo o Instituto Mineiro de Agropecuária, a atividade gera cerca de 120 mil empregos diretos e 40 mil empregos indiretos (Martins, 2001). Cerca de 68\% da produção de queijo-de-minas artesanal concentra-se nas regiões do Serro, de Araxá e da Serra da Canastra (Martins, 2001).

O queijo-de-minas do Serro, considerado uma variedade do queijo-de-minas, é fabricado a partir do leite cru adicionado do "pingo" e do coalho. O "pingo" é uma porção de soro fermentado originado do dessoramento de queijos produzidos no dia anterior e que é coletado em vasilhames para ser utilizado como fermento. $\mathrm{O}$ pingo é responsável pelas características sensoriais tradicionais e peculiares do queijo-de-minas artesanal (Leite, 1993). A fabricação do queijo-de-minas artesanal do Serro é doméstica e desprovida de mecanização, sendo o local de produção chamado de "casa de queijo" ou "quarto de queijo" e, geralmente, localiza-se ao lado do curral, ligado a ele por uma janela.

Como o queijo-de-minas artesanal do Serro é fabricado a partir de leite cru e não é submetido a tratamento térmico, o risco de ser veiculador de microrganismos patogênicos resulta em importante questão de saúde pública (Pinto et al., 1996; Loguercio e Aleixo, 2001).

Este trabalho foi realizado com o objetivo de avaliar a qualidade microbiológica do queijo-deminas artesanal do Serro e observar a variação da microbiota do queijo recém-fabricado e no último dia do prazo de validade.

\section{MATERIAL E MÉTODOS}

Foram coletados queijos-de-minas, produzidos na região do Serro-MG, de produtores de diversas escalas de produção, escolhidos aleatoriamente. As amostras foram provenientes da cooperativa responsável pelo recebimento, embalagem e identificação dos queijos produzidos nas propriedades rurais da região, que as encaminharam ao CEASA em ContagemMG. O transporte das amostras até o CEASA foi realizado em caminhão refrigerado. Até o laboratório, foram utilizadas caixas isotérmicas com gelo reciclável.
Foram analisadas 40 amostras de queijos-deminas, sendo 20 logo após a coleta e 20 após a estocagem a $10^{\circ} \mathrm{C}$, em câmara fria, até a data final do prazo de validade, isto é, 30 dias.

As amostras foram analisadas quanto ao número mais provável de coliformes a $35^{\circ} \mathrm{C}$ e a $45^{\circ} \mathrm{C}$, contagem de Staphylococcus coagulase positiva, presença de Salmonella spp. e Listeria monocytogenes, de acordo com Bacteriological... (1998). As análises foram realizadas assepticamente, com o uso de chama dentro de capelas de fluxo laminar, seguindo os mesmos protocolos oficiais de rotina do laboratório.

Os resultados foram analisados de acordo com a resolução: RDC ANVISA $n^{\circ} 12 / 01$, sendo as amostras consideradas impróprias ao consumo humano quando ultrapassavam o limite estabelecido.

Realizou-se uma análise estatística descritiva para avaliar a porcentagem de amostras fora do padrão estabelecido em legislação específica, determinando o número de amostras impróprias ao consumo humano. Com relação às contagens de Staphylococcus coagulase positiva, foram calculadas algumas medidas descritivas, estabelecendo-se média, desvio-padrão e variância com transformação logarítmica dos dados para aproximá-los da distribuição normal. Os programas utilizados foram o software SPSS 9.0 e Minitab 12, ambos para Windows.

\section{RESULTADOS E DISCUSSÃO}

Das 40 amostras de queijo analisadas, 37 (92,5\%) apresentaram-se impróprias ao consumo humano, resultados semelhantes aos obtidos por Tomich et al. (2001), que encontraram 93\% das 14 amostras de queijo-de-minas da região de Belo Horizonte impróprias ao consumo, aos de Nascimento et al. (2001), que pesquisaram 17 amostras de queijo coalho da região metropolitana de Fortaleza, das quais 94\% estavam fora dos padrões vigentes e aos de Rocha et al. (2006), que ao analisarem sete marcas de queijo-de-minas frescal, verificaram em seis delas, índices de contaminação por $S$. aureus acima do recomendado. Loguercio e Aleixo (2001), ao pesquisarem queijo-de-minas frescal, encontraram $97 \%$ de amostras em desacordo com a legislação em relação à 
contagem de $S$. aureus e Laicini et al. (1993), ao analisarem laudos analíticos do Instituto Adolfo Lutz de 1989 a 1990, constataram 92\% das amostras de queijos-de-minas em desacordo com os padrões legais.

A contagem de coliformes a $35^{\circ} \mathrm{C}$ não é exigida pela legislação sanitária vigente, entretanto, como esses microrganismos geralmente são contaminantes ambientais, sua contagem elevada indica deficiência na qualidade higiênicosanitária do produto. Trinta e duas amostras $(80 \%)$ apresentaram coliformes a $35^{\circ} \mathrm{C}$ acima de $5 \times 10^{3} / \mathrm{g}$. Oliveira et al. (1998), pesquisando 32 amostras de queijo-de-minas industrializado, encontraram $46,9 \%$ de amostras com contagens de coliformes a $35^{\circ} \mathrm{C}$ acima de $5 \times 10^{3} / \mathrm{g}$.

Vinte e quatro amostras (60\%) apresentaram coliformes a $45^{\circ} \mathrm{C}$ acima de $5 \times 10^{3}$ UFC/grama, todas impróprias para consumo humano de acordo com a contagem tolerada pela resolução: RDC ANVISA $\mathrm{n}^{\circ} 12 / 01$. Ao investigar a qualidade de queijo-de-minas, Peresi et al. (2001) constataram que $43,3 \%$ das 30 amostras de queijo-de-minas artesanal analisadas estavam em desacordo quanto ao número de coliformes a $45^{\circ} \mathrm{C}$, enquanto Loguercio e Aleixo (2001), pesquisando 30 amostras de queijo-de-minas frescal, encontraram $93 \%$ de amostras em desacordo com a legislação com relação à determinação de coliformes fecais. Rocha et al. (2006), também verificaram contagens de coliformes acima de $5 \times 10^{3} / \mathrm{g}$ em $61 \%$ das amostras de queijo-de-minas analisadas. Os diferentes resultados sugerem que distintas condições de fabricação do queijo podem resultar em diferentes níveis de contaminação.

Trinta e três amostras (82,5\%) apresentaram contagens de Staphylococcus coagulase positiva acima de $10^{3} \mathrm{UFC} /$ grama, estando impróprias ao consumo humano. Este microrganismo foi $\mathrm{o}$ contaminante mais freqüente, e a contagem média foi de $1,2 \times 10^{6} \mathrm{UFC} / \mathrm{g}$, sendo que 21 amostras (53\%) apresentaram contagens acima de $10^{5} \mathrm{UFC} / \mathrm{g}$. Neste caso, há o risco de produção de enterotoxinas (Nicolau et al., 2001).

Os resultados do presente experimento são similares aos relatados por Lubeck et al. (2001) que verificaram $100 \%$ das amostras de queijos coloniais da região do Paraná contaminadas com elevadas contagens de $S$. aureus, sendo a

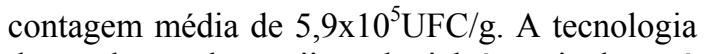
de produção do queijo colonial é equivalente à do queijo-de-minas artesanal. Almeida Filho e Nader Filho (2000) analisaram 80 amostras de queijos-de-minas fabricados artesanalmente, das quais $40(50 \%)$ apresentaram-se impróprias para o consumo humano quanto à contagem de $S$. aureus. Em Belo Horizonte, Cerqueira et al. (1997) encontraram 43,3\% das amostras de queijo-de-minas curado artesanal com contagens de Staphylococcus sp. de $10^{2}$ a $10^{6} \mathrm{UFC} / \mathrm{g}$. Peresi et al. (2001) analisaram 30 amostras de queijos Minas artesanal e encontraram $60 \%$ das amostras impróprias ao consumo humano, devido à contagem de Staphylococcus coagulase positiva. Loguercio e Aleixo (2001) verificaram, em 29 das 30 amostras de queijo-de-minas frescal analisadas, contagens de $S$. aureus acima de $10^{3} \mathrm{UFC} / \mathrm{g}$. Vilela et al. (2001), entretanto, ao analisarem 70 amostras de queijos-de-minas, processados industrialmente em pequenos laticínios da região de Juiz de Fora-MG, encontraram $15,7 \%$ dessas impróprias para o consumo humano.

As condições sanitárias dos rebanhos, a qualidade do leite, as condições higiênicosanitárias de fabricação, transporte e comercialização e o tempo e temperatura de conservação dos queijos durante a estocagem podem explicar a variabilidade dos percentuais de amostras impróprias ao consumo humano.

A contaminação da maioria das amostras de queijos artesanais por Staphylococcus coagulase positiva pode ser explicada pelo fato de as principais fontes de contaminação do queijo serem a matéria-prima e a manipulação por pessoas portadoras desse microrganismo. A contagem de Staphylococcus coagulase positiva de queijos recém-fabricados e estocados estão dispostos na Tab. 1. A média logarítmica do número de Staphylococcus coagulase positiva para os queijos recém-fabricados é mais alta que a média logarítmica do número de Staphylococcus coagulase positiva para os queijos estocados a $10^{\circ} \mathrm{C} \quad(\mathrm{P}<0,01)$. Este resultado deveu-se provavelmente às condições de meio $(\mathrm{pH}$, atividade de água, inibidores naturais presentes, dentre outros) menos favoráveis à sobrevivência do patógeno no queijo estocado. Embora tenha ocorrido diminuição na população desse microrganismo, ressalta-se que as toxinas, uma vez produzidas, são resistentes às 
condições de estocagem verificadas neste experimento.

Tabela 1. Contagem de Staphylococcus coagulase positiva de queijos recém-fabricados e armazenados por 30 dias a $10^{\circ} \mathrm{C}$

\begin{tabular}{lcc}
\hline Amostra analisada & $\begin{array}{c}\text { Contaminação } \\
(\log U F C / g)\end{array}$ & P \\
\hline $\begin{array}{l}\text { Queijo recém- } \\
\text { fabricado }\end{array}$ & $5,4 \pm 1,0$ & \\
Queijo estocado & $4,1 \pm 1,6$ & 0,0058 \\
\hline
\end{tabular}

Nenhuma amostra de queijo apresentou contaminação por Salmonella spp ou Listeria monocytogenes. Peresi et al. (2001), também não encontraram Listeria monocytogenes ao pesquisarem queijo-de-minas adquirido em feiras livres de São José do Rio Preto, verificaram, entretanto, duas amostras (6,7\%) com presença de Salmonella sp. Corbia et al. (1999) e Silva et al. (1999) também não encontraram $L$. monocytogenes em queijo-de-minas frescal. A ausência de Salmonella sp. e de Listeria monocytogenes pode ter sido causada pela menor capacidade de competição dessas espécies, em relação aos coliformes e ao Staphylococcus sp. A ocorrência desses microrganismos em alimentos está, muitas vezes, associada às contagens menores de outros contaminantes.

\section{CONCLUSÕES}

A maioria das amostras de queijo-de-minas artesanal do Serro analisadas neste experimento encontra-se em desacordo com os padrões exigidos legalmente. O queijo-de-minas artesanal do Serro pode oferecer risco à saúde do consumidor por apresentar elevada contaminação por Staphylococcus coagulase positiva. Houve diferença significativa nas contagens de Staphylococcus coagulase positiva entre os queijos recém-fabricados e os queijos estocados sob refrigeração nas condições recomendadas no rótulo.

\section{AGRADECIMENTOS}

À FUNED e à CAPES.

\section{REFERÊNCIAS BIBLIOGRÁFICAS}

ALMEIDA FILHO, E.S.; NADER FILHO, A. Ocorrência de Staphylococcus aureus em queijo tipo "frescal". Rev. Saúde Publ., v.34, p.578-580, 2000 .

BACTERIOLOGICAL analytical manual. 8.ed. Arlington: AOAC/FDA, 1998.

CERQUEIRA, M.M.O.P.; LEITE, M.O.; SOUZA, M.R. et al. Freqüência de Listeria sp. e de Staphylococcus aureus em queijo Minas produzido artesanalmente. Rev. Inst. Lat. Cândido Tostes, v.51, p.17-20, 1997.

CORBIA, A.C.G.; NASCIMENTO, M.G.F.; OLIVEIRA, C.Z.F. et al. Pesquisa de Listeria monocytogenes em queijo tipo minas frescal. In: CONGRESSO BRASILEIRO DE MICROBIOLOGIA， 20., 1999, Salvador. Anais..., Salvador, 1999. p. 387.

FURTADO, M.M. Queijo do Serro: tradição na história do povo mineiro. Rev. Inst. Lat. Cândido Tostes, v.35, p.33-36, 1980.

LAICINI, Z.M.; PARMEZZANI, A.F.; PAULA, S.R. et al. Avaliação dos laudos analíticos das amostras de alguns tipos de queijos recebidos pelo instituto Adolfo Lutz de Ribeirão Preto. Rev. Inst. Adolfo Lutz, v.53, p.17-20, 1993.

LEITE, M.O. Isolamento e seleção de culturas lácticas nacionais resistentes a bacteriófagos para elaboração de queijo Minas curado. 1993. 64f. Dissertação (Mestrado) - Departamento de Tecnologia de Alimentos, Universidade Federal de Viçosa, Viçosa, MG.

LOGUERCIO, A.P.; ALEIXO, J.A.G. Microbiologia de queijo tipo Minas frescal produzido artesanalmente. Cien. Rural, v.31, p.1063-1067, 2001.

LUBECK, G.M.; LARA, J.A. F.; BAGATINI, L. et al. Avaliação de algumas características físicoquímicas e microbiológicas de algumas marcas de queijo tipo colonial produzido no sudoeste do estado do Paraná. Rev. Inst. Lat. Cândido Tostes, v.56, p.185-193, 2001.

MARTINS, E. Patrimônio de Minas. Rev. Econ. Jornal Estado de Minas, n.44, p. 14-17, dez 2001. 
NASCIMENTO, F.R.R.; QUEIROZ, E.L.; ARCANJO, S.R S. et al. Ações da vigilância sanitária perante as condições higiênicosanitárias do queijo Coalho comercializado no município de Fortaleza. Rev. Inst. Lat. Cândido Tostes, v.56, p.257-261, 2001.

NICOLAU, E.S.; KUAYE, A.Y.; Mesquita, A.J. et al. Avaliação do potencial de produção e tipos de enterotoxinas estafilocócica encontradas em linhagens de Staphylococcus aureus e extratos de amostras de queijo tipo mussarela fabricado na região de Goiânia-GO. Rev. Inst. Lat. Cândido Tostes, v.56, p.92-101, 2001.

OLIVEIRA, C.A.F.; MORENO, J.F.G.; MESTIERI, L. et al. Características físicoquímicas e microbiológicas de queijos Minas frescal e mussarela, produzidos em algumas fábricas de laticínios do estado de São Paulo. Hig. Alim., v.12, p.31-35, 1998.

PERESI, J.T.M.; GRACIANO, R.A.S.; ALMEIDA, I.A.Z.C. et al. Queijo Minas tipo frescal artesanal e industrial: qualidade microscópica, microbiológica e teste de sensibilidade aos agentes antimicrobianos. Hig. Alim., v.15, p.63-70, 2001.
PINTO, P.S.A.; GERMANO, M.I.S.; GERMANO, P.M.L. Queijo Minas: problema emergente da vigilância sanitária. Hig. Alim., v.10, p.22-27, 1996.

ROCHA, J.S.; BURITI, F.C.A.; SAAD, S.M.I. Condições de processamento e comercialização de queijo-de-minas frescal. Arq. Bras. Med. Vet. Zootec., v.58, p.263-272, 2006.

TOMICH, R.G.P.; TOMICH, T.R.; ORNELAS, E.A. et al. Qualidade microbiológica de queijo Minas utilizado como matéria-prima na fabricação de pão de queijo. Rev. Inst. Lat. Cândido Tostes, v.56, p.62-68, 2001.

SILVA, I.M.M.; ALMEIDA, R.C.C.; ALMEIDA, P.F. et al. Presença de Listeria sp. no processamento de queijo minas frescal em um laticínio da Bahia. In: CONGRESSO BRASILEIRO DE MICROBIOLOGIA, 20., 1999, Salvador. Anais..., Salvador, 1999. p.369.

VILELA, M.A.P.; REZENDE, P.R.; MEURER, V.M. et al. Incidência de estafilococos produtores de coagulase em queijo Minas frescal comercializado na cidade de Juiz de Fora e região. Rev. Inst. Lat. Cândido Tostes, v.56, p.140-143, 2001. 